\title{
Interleukin-24 Transduction Modulates Human Prostate Cancer Malignancy Mediated by Regulation of Anchorage Dependence
}

\author{
SHOTARO MAEHANA ${ }^{1,2}$, YUTA MATSUMOTO ${ }^{1}$, FUMIAKI KOJIMA ${ }^{3}$ and HIDERO KITASATO ${ }^{1,2}$ \\ ${ }^{1}$ Department of Microbiology, Kitasato University School of Allied Health Science, Kanagawa, Japan; \\ ${ }^{2}$ Department of Environmental Microbiology, Kitasato University Graduate School of Medical Sciences, Kanagawa, Japan; \\ ${ }^{3}$ Department of Pharmacology, Kitasato University School of Allied Health Sciences, Kanagawa, Japan
}

\begin{abstract}
Background: Hormone therapy and chemotherapy are not effective for castrate-resistant prostate cancer, thus development of novel treatment strategies is required. Gene therapy involving transient high-copy transfection of interleukin (IL)-24 with an adenoviral vector can exert antitumor activity; however, the effects of stable IL-24 transfection are not fully understood. The aim of this study was to investigate the effects of IL-24 overexpression in prostate cancer cells, in vitro. Materials and Methods: DU145 cells were transfected the IL-24 gene using a retroviral vector. Apoptosis induction was investigated by the cell death detection ELISA, and the gene expression was analyzed by real time RT-PCR. Results: IL-24 transduction suppressed the growth of prostate cancer and induced tumor cell apoptosis. In addition, up-regulation of epithelial markers and down-regulation of mesenchymal markers were noted, suggesting that tumor aggressiveness was reduced. Conclusion: Introduction of IL-24 displays antitumor activity both by induction of apoptosis and regulation of anchorage dependence.
\end{abstract}

Prostate cancer has the highest cancer morbidity rate and is the second most frequent cause of cancer-related death in the USA, being one of the most frequent malignancies among men (1). Prostate cancer often progresses silently and may cause metastases, especially in osseous sites (2). Early detection of prostate cancer by measurement of prostate specific antigen has led to a rapid increase of patients with this tumor type $(3,4)$.

Since it is difficult to effectively control metastatic castrate-resistant prostate cancer with hormone therapy or chemotherapy $(5,6)$, development of new treatments is

Correspondence to: Shotaro Maehana, Department of Microbiology, Kitasato University School of Allied Health Science, 1-15-1 Kitasato, Minami-Ku, Sagamihara, Kanagawa, 252-0373, Japan. Tel.: +81 427788072, Fax: +81 427789400, e-mail: smaehana@kitasato-u.ac.jp

Key Words: IL-24, prostate cancer, anchorage dependence, stable retroviral transfection. required. Interleukin-24 (IL-24), member of the IL-10 family, is a monomeric glycoprotein with a molecular weight ranging from 35 to $40 \mathrm{kDa}$ that is mainly produced by splenocytes and peripheral blood leukocytes (7-9). The IL-24 receptor has two heteroforms, IL-20RA/IL-20RB and IL-22RA/IL-20RB (10), and binding of IL-24 to these receptors activates the JAK/STAT signaling pathway in normal cells (11).

IL-24 (also known as MDA-7) was initially discovered as an antitumor factor that suppressed the growth of melanoma cells and promoted their terminal differentiation after treatment with interferon and mezerein $(12,13)$. It was reported that IL-24 gene expression in cancer cells shows a negative correlation with tumor invasion and metastasis (14, 15). Introduction of the IL-24 gene using an adenoviral vector suppresses the growth of several types of tumor cells, while having no such effect on normal cells $(16,17)$. According to previous studies, transient adenovirus-based transfection of cancer cells with IL-24 shows antitumor activity by induction of endoplasmic reticulum stress and activation of caspases; however, the effect of constitutive IL24 expression is unknown.

In this study, we established a prostate cancer cell line with stable overexpression of IL-24 by using a retroviral vector. The growth inhibitory effect of IL-24 was investigated by evaluation of cell viability, BrdU incorporation, and apoptosis. We also observed other antitumor effects after retroviral introduction of IL-24, such as regulation of anchorage dependence.

\section{Materials and Methods}

Cells and reagents. The human prostate cancer cell line DU145 (\#RCB2143; Riken BioResource Center, Tsukuba, Japan) was cultured at $37^{\circ} \mathrm{C}$ in RPMI 1640 medium (Sigma Aldrich, Tokyo, Japan) supplemented with $10 \%$ fetal bovine serum (FBS; Gibco by Thermo Fisher Scientific, Waltham, NY, USA) and 100 units $/ \mathrm{ml}$ of penicillin plus $10 \mu \mathrm{g} / \mathrm{ml}$ of streptomycin (Gibco, Tokyo, Japan) under a humidified atmosphere of $95 \%$ air and $5 \% \mathrm{CO}_{2}$.

A packaging cell line (PT67) was purchased from Clontech (via Takara Bio Inc., Tokyo, Japan) and NIH/3T3 cells were kindly provided 
by Dr. Majima (Kitasato University School of Medicine), with both cell lines being cultured at $37^{\circ} \mathrm{C}$ in Dulbecco's modified Eagle's medium (DMEM; Sigma Aldrich, St. Louis, MO, USA) supplemented with $10 \% \mathrm{FBS}$ and $100 \mathrm{units} / \mathrm{ml}$ of penicillin plus $10 \mu \mathrm{g} / \mathrm{ml}$ of streptomycin under a humidified atmosphere of $95 \%$ air and $5 \% \mathrm{CO}_{2}$.

Recombinant human IL-24 (rhIL-24) was purchased from R\&D Systems (Minneapolis, MN, USA).

Introduction of the IL-24 gene. Human IL-24 cDNA was synthesized by Medical \& Biological Laboratories (BML, Aichi, Japan) and a recombinant plasmid was designed (pSMARTIDThIL-24). After pSMARTIDT-hIL-24 was digested with Not I and $\mathrm{Cla} \mathrm{I}$, the resulting fragments were cloned into the Not I/Cla I sites of the pBlueScript SK II amplification vector (pBluescripthIL-24). Next, the Not I/Cla I fragments were cloned into the pDON-5 Neo deficient retroviral vector to obtain pDON-hIL-24, which was subsequently transfected into PT67 packaging cells, followed by selection with G418 to obtain PT67-hIL-24 cells. PT67 packaging cells only transfected with pDON5-Neo were used as a control (PT67-EV cells). The IL-24 sequence cloned into pDON-5 neo was determined by DNA sequencing using an ABI 3100 genetic analyzer (Applied Biosystems by Thermo Fisher Scientific), and was verified by comparison with a database (accession no. BC009681).

To evaluate the infectious titer of recombinant retrovirus containing the hIL-24 gene in the culture supernatant of PT67-hIL24 and PT67-EV cells, supernatant diluted by $10^{-1}$ to $10^{-5}$ was used to infect $5 \times 10^{4} \mathrm{NIH} / 3 \mathrm{~T} 3$ fibroblasts, followed by selection with G418 antibiotic. The retroviral vector was also used to infect LLC cells, followed by selection with G418. The resulting cell lines were designated as DU145-hIL-24 and DU145-EV, respectively.

$R T-P C R$ and real time RT-PCR. Genomic DNA-free total RNA was extracted and purified from cells or tumor tissues by using the RNeasy Plus Mini Kit (Qiagen, Venlo, Netherlands) and the TURBO DNA-free Kit (Ambion by Thermo Fisher Scientific). Then $2 \mu \mathrm{g}$ of total RNA was used for synthesis of cDNA with Omniscript RT Kit (Qiagen) in a total volume of $20 \mu$ l.

A $1 \mu \mathrm{l}$ aliquot of CDNA was submitted for PCR in a volume of $50 \mu$ l. PCR involved activation at $94^{\circ} \mathrm{C}$ for $15 \mathrm{~min}$, followed by 30 cycles of denaturation at $94^{\circ} \mathrm{C}$ for $1 \mathrm{~min}$, annealing at $60^{\circ} \mathrm{C}$ for 1 min, and extension at $72^{\circ} \mathrm{C}$ for 2 min using a thermal cycler (GeneAmpPCR System 9700: Applied Biosystems) and SYBR Premix Dimer Eraser (Takara Bio Inc.). The oligonucleotide primers are listed in Table I.

ELISA. DU145-hIL-24 cells or DU145-EV cells were seeded at a density of $5 \times 10^{4}$ cells/well in 6 -well culture plates (AGC Techno Glass, Shizuoka, Japan) and then incubated for $24 \mathrm{~h}$. After medium exchange, culture was continued for another $48 \mathrm{~h}$ and the supernatant was collected by centrifugation at 1,500 rpm for $5 \mathrm{~min}$. The IL-24 level in the supernatant was analyzed by using a Human IL-24 DuoSet ELISA kit (R\&D Systems).

Cell proliferation assay. DU145-hIL-24 cells or DU145-EV cells were seeded at a density of $1 \times 10^{3}$ cells/well in 96-well culture plates (AGC Techno Glass) and then incubated for $24 \mathrm{~h}$. After medium exchange, culture was continued for another $96 \mathrm{~h}$, and then cell proliferation was investigated by the WST assay (Cell Counting Kit-8; Dojindo Laboratories, Kumamoto, Japan) and a BrdU ELISA Kit (Roche, Mannheim, Germany).
Phalloidin staining. DU145-hIL-24 cells or DU145-EV cells were seeded at a density of $5 \times 10^{3}$ cells on $13 \mathrm{~mm}$ diameter poly-Llysine-coated cover slips (Matsunami Glass Ind., Osaka, Japan) placed at the bottom of a 24-well culture plate (AGC Techno Glass), and then were incubated for $24 \mathrm{~h}$. After culture for an additional $96 \mathrm{~h}$, cells were fixed in 4\% PFA, rinsed three times in PBS, permeabilized with $0.1 \%$ Triton-X in PBS, and rinsed three times in PBS. Subsequently, the cells were stained with phalloidin conjugate solution (Abcam, Cambridge, UK) at room temperature for $90 \mathrm{~min}$, and then were rinsed four times in PBS. Finally, the cells were mounted by using Vectashield HardSet Antifade Mounting Medium with DAPI (Vector Laboratories, Burlingame, CA, USA), and were observed under a type BZ-9000 fluorescence microscope (Keyence, Osaka, Japan).

Detection of apoptosis. DU145-hIL-24 cells or DU145-EV cells were seeded at a density of $1.0 \times 10^{3}$ cells/well in 96-well culture plates, and then incubated for $24 \mathrm{~h}$. After culture for a further $96 \mathrm{~h}$, the cells were lysed and apoptosis was investigated by a cell death detection ELISA Plus Kit (Roche, Mannheim, Germany) after removal of the culture medium.

Statistical analysis. All experiments were conducted three times. Results are expressed as the mean \pm standard deviation (SD). Comparisons between two groups were performed using Student's $t$-test and $p<0.05$ was considered to indicate statistical significance.

\section{Results}

Characterization of DU145-hIL-24 cells. The process of constructing pDON-5 Neo-hIL-24 is summarized in Figure 1A. A defective retrovirus vector was assembled using pDON-5 Neo-hIL-24 and was employed to infect DU145 cells at a MOI of $10^{-4}$ to obtain DU145-hIL-24 cells. IL-24 mRNA (429 bp) was clearly expressed in DU-145-hIL-24 cells, but was undetectable in control DU145-EV cells. On the other hand, expression of the neomycin resistance gene derived from the retroviral vector ( $\mathrm{NeO}$ ) and expression of glyceraldehyde 3-phosphate dehydrogenase (GAPDH) were clearly seen in both cell lines (Figure 1B). In culture supernatant of DU145-IL-24 cells, the IL-24 protein concentration was $3.8 \mathrm{ng} / \mathrm{ml}$, but IL-24 was undetectable in the supernatant of DU145-EV cells (Figure 1C).

Induction of apoptosis in DU145-hIL-24 cells. Proliferation of DU145-hIL-24 and DU145-EV cells was evaluated by the WST assay and by ELISA for BrdU. At $96 \mathrm{~h}$ after cell seeding, proliferation of DU145-IL-24 cells was about 30\% lower compared to DU145-EV cells, according to the WST assay and BrdU ELISA (Figure 2A and B).

A cell death detection ELISA was also performed to determine whether the suppressive effect of IL-24 on cell proliferation was associated with apoptosis. This showed that apoptosis was elevated by approximately $50 \%$ in DU145-hIL-24 cells compared with DU145-EV cells (Figure 2C). 
Table I. Primer sequences.

\begin{tabular}{|c|c|c|}
\hline Target gene & $\begin{array}{l}\text { Product } \\
\text { length }\end{array}$ & Sequence $\left(5^{\prime}-3^{\prime}\right)$ \\
\hline GAPDH & 190 (bp) & $\begin{array}{l}\text { F: TGGCTACAGCAACAGGGTGGTG } \\
\text { R: TTCAAGGGGTCTACATGGCAACTG }\end{array}$ \\
\hline IL-24 & 429 (bp) & $\begin{array}{l}\text { F: GACTTTAGCCAGCAGACCCTT } \\
\text { R: GGTTGCAGTTGTGACACGAT }\end{array}$ \\
\hline Neo & 515 (bp) & $\begin{array}{l}\text { F: GGGCGCCCGGTTCTTTTTG } \\
\text { R: ACACCCAGCCGGCCACAGTCG }\end{array}$ \\
\hline IL-20RA & 682 (bp) & $\begin{array}{l}\text { F: CCAGCTTCGACCAGGATTCA } \\
\text { R: ATGCGACCAACTTACCACCA }\end{array}$ \\
\hline IL-22RA & 481 (bp) & $\begin{array}{l}\text { F: CTGTCCGAGATCACCTACTTAGG } \\
\text { R: GCACATTTGGGTCAGATGTTCTGTC }\end{array}$ \\
\hline IL-20RB & 480 (bp) & $\begin{array}{l}\text { F: CAGGTGAAGCCGAGAACCTG } \\
\text { R: CAAGCCACCCAGTGTGTAGA }\end{array}$ \\
\hline E-cadherin & 103 (bp) & $\begin{array}{l}\text { F: TGCACCAACCCTCATGAGTG } \\
\text { R: GTCAGTATCAGCCGCTTTCAG }\end{array}$ \\
\hline Fibronectin 1 & 97 (bp) & $\begin{array}{l}\text { F: TCGCCATCAGTAGAAGGTAGCA } \\
\text { R: TGTTATACTGAACACCAGGTTGCA }\end{array}$ \\
\hline$\alpha$-SMA & 88 (bp) & $\begin{array}{l}\text { F: CCGACCGAATGCAGAAGGA } \\
\text { R: ACAGAGTATTTGCGCTCCGGA }\end{array}$ \\
\hline $\operatorname{smad} 7$ & 82 (bp) & $\begin{array}{l}\text { F: GCCGACTCTGCGAACTAGAGT } \\
\text { R: GGACAGTCTGCAGTTGGTTTGA }\end{array}$ \\
\hline
\end{tabular}

F, Forward; R, reverse.
A

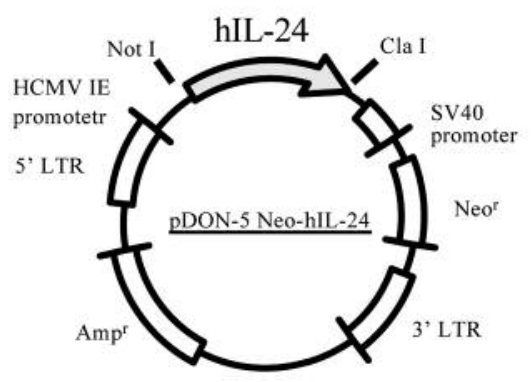

B DU145-EV DU145-hIL-24

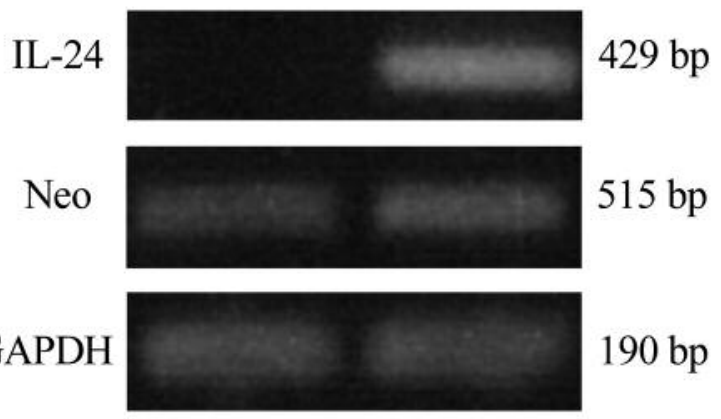

Apoptotic effect of IL-24 not mediated via the IL-24 receptor. To investigate whether the antitumor effect of IL-24 was mediated via IL-24 receptor signaling, tumor cells were exposed to endogenous rhIL-24. It was found that endogenous rhIL-24 had no effect on cell proliferation, even at a high concentration $(10 \mathrm{ng} / \mathrm{ml})$ (Figure 3A). In addition, expression of IL-24 heteroreceptors (IL-20RA, IL-22RA, and IL-20RB) was not found in DU145 cells, but was detected in PC-3 control cells (Figure 3B). These results imply that the antitumor effect of introduced IL-24 was independent of IL-24 receptor signaling.

Morphological changes of DU145-hIL-24 cells. Microscopy showed that DU145-hIL-24 cells grew more densely in comparison with DU145-EV cells. Fluorescent staining of actin filaments was performed to evaluate motility, and stress fibers were detected in DU145-EV cells, but not in DU145hIL-24 cells (Figure 4A). To investigate this difference of actin filament formation, quantitative analysis of epithelial and mesenchymal markers was performed by real time RTPCR. This revealed that expression of the mesenchymal markers fibronectin 1 and alpha-smooth muscle actin $(\alpha-$ SMA) was significantly decreased in DU145-IL-24 cells compared to DU145-EV cells (Figure 4B). These results indicated that introduction of IL-24 influenced the regulation of anchorage dependence.

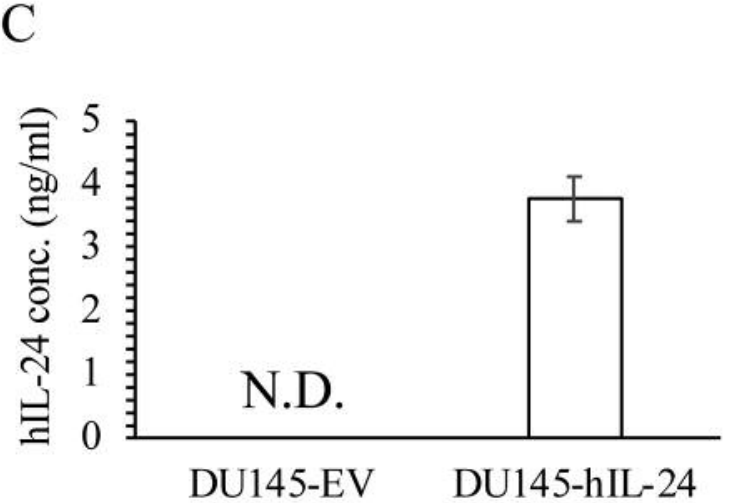

Figure 1. Transfection of the human interleukin-24 (hIL-24) gene and its expression in prostate cancer cells. The human IL-24 gene was introduced by using a defective retroviral vector that integrated into genomic DNA and stably expressed the target gene. The hIL-24 gene was cloned into the NotI to ClaI site of the pDON-5 neo retroviral vector (designated as pDON-5 Neo-hIL-24) (A). DU145 cells were infected with pDON-5 neo-IL-24, followed by G418 selection to obtain DU145-hIL-24 cells. DU145 cells were also infected with the pDON-5 Neo empty vector to obtain control DU145-EV cells. RT-PCR was performed to assess $m R N A$ expression by DU145-IL-24 and DU145-EV cells $(B)$. Production of hIL-24 protein into culture supernatant after incubation for $48 \mathrm{~h}$ was detected by ELISA. N.D., Not detected (C). Data are the mean $\pm S D$. ${ }^{*} p<0.01$ (compared to DU145-EV cells). 

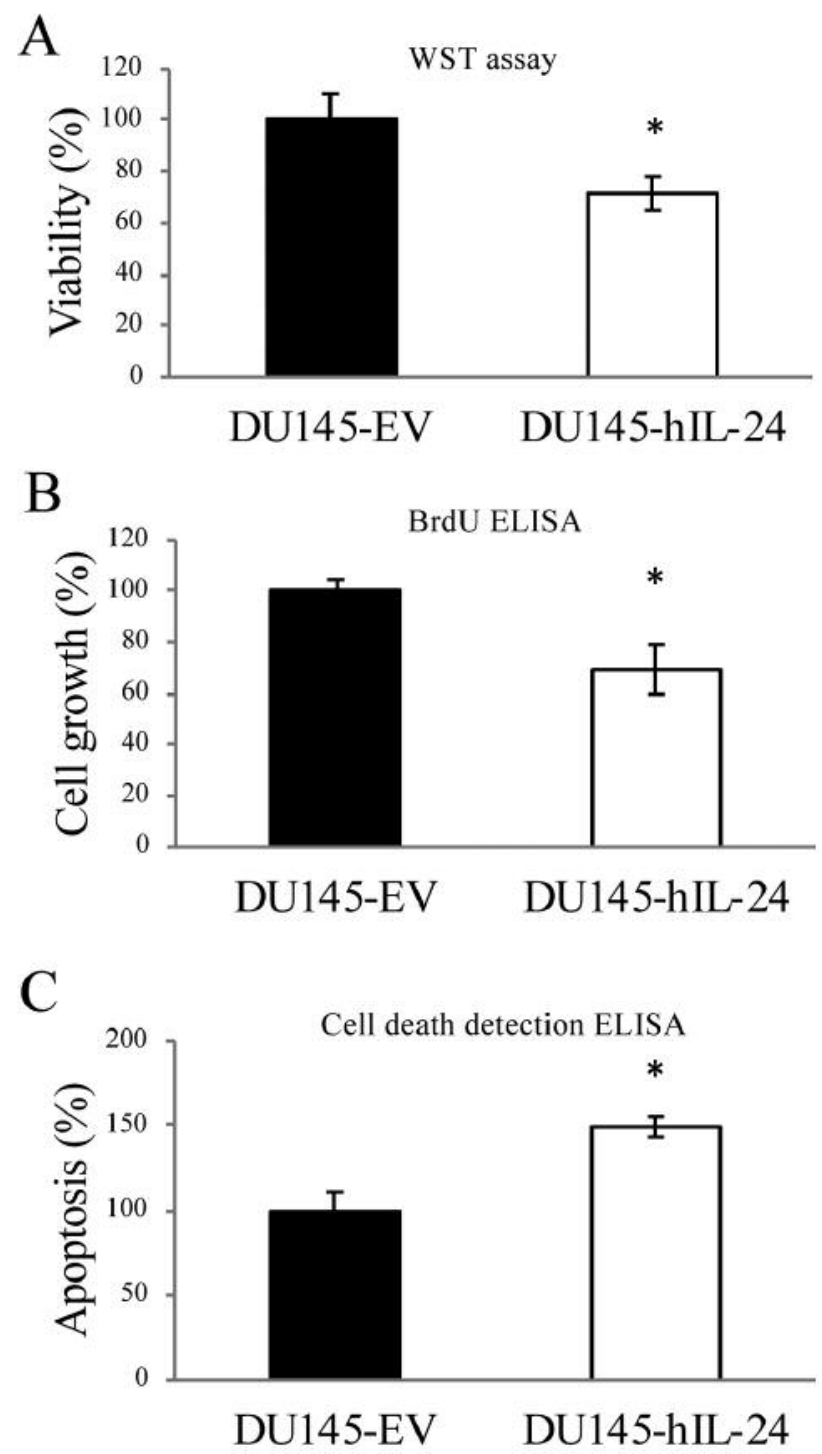

Figure 2. Antitumor effect of interleukin-24 (IL-24) in DU145-hIL-24 prostate cancer cells. The cells were cultured for $96 \mathrm{~h}$ before performing growth and apoptosis assays. Tumor cell viability (A) and growth (B) were assessed by the WST assay and BrdU ELISA, respectively. Apoptosis was analyzed with cell death detection ELISA (C). Data are the mean $\pm S D$ and a representative result of three experiments is shown. $* p<0.05$ (compared to DU145-EV cells).

\section{Discussion}

In this study, we investigated the antitumor effect of retroviral transduction of IL-24 in prostate cancer cells, and we demonstrated that this led to inhibition of cell growth and viability along with induction of apoptosis. In addition, motility of the cancer cells was affected, with reduction of stress fiber formation and downregulation of fibronectin expression. Interestingly, the cancer cells did not express IL-
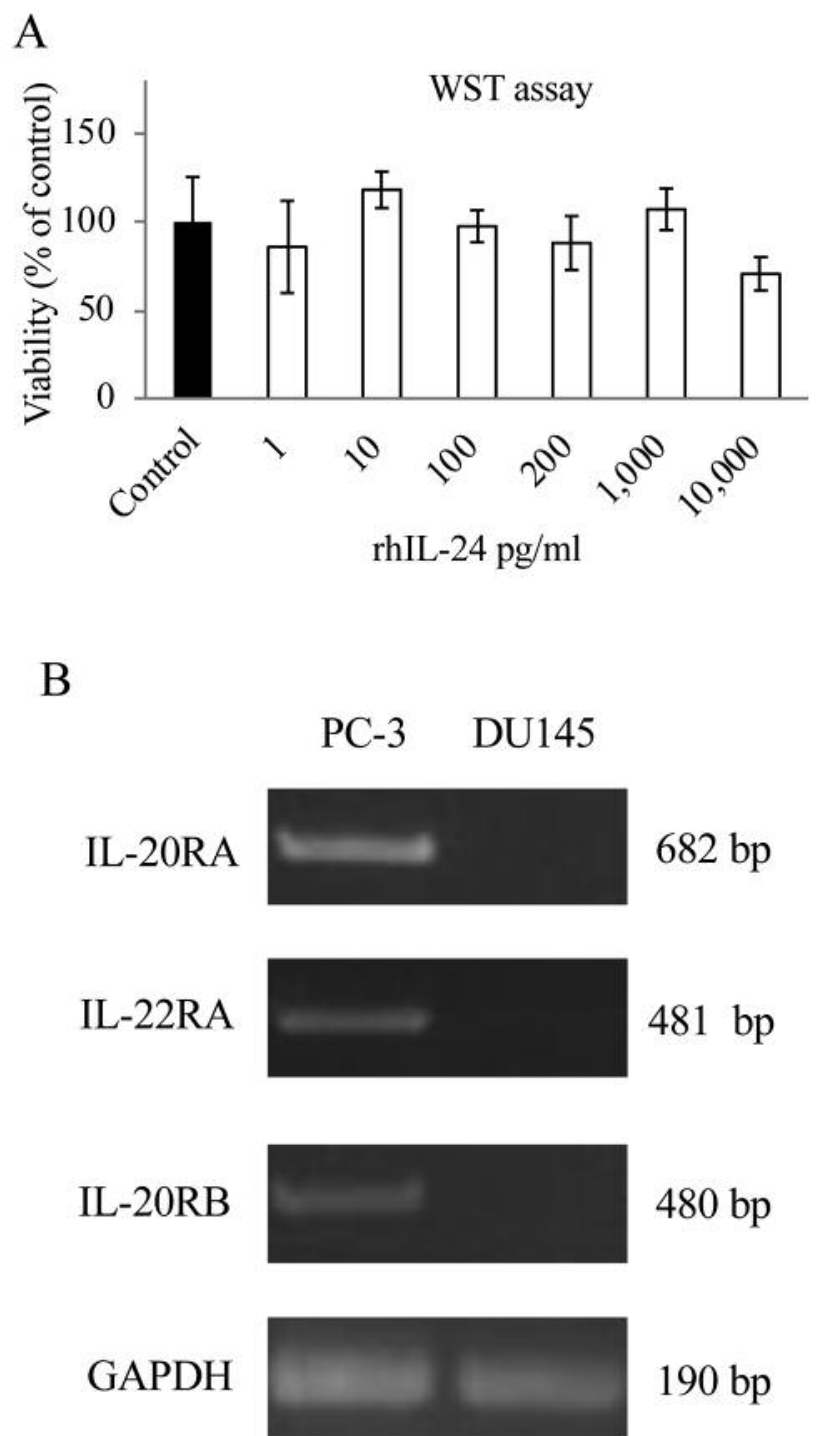

Figure 3. Effect of recombinant human interleukin-24 (hIL-24) and IL24 receptor (IL-20RA, IL-22RA, and IL-20RB) expression by tumor cells. DU145 cells were cultured in medium containing rIL-24 or PBS control for $96 \mathrm{~h}$, after which growth was assessed by the WST-8 assay (A). IL-24 receptor expression was detected by RT-PCR (B). Data are the mean $\pm S D$ and a representative result of three experiments is shown.

24 receptors and were insensitive to recombinant IL-24. These results suggest that introduction of IL-24 into cancer cells displays antitumor activity by both induction of apoptosis and regulation of anchorage dependence via intracellular signaling.

Thus, we found that transduction of IL-24 via a retroviral vector showed antitumor activity. Further investigation indicated that BrdU incorporation during cell division and induction of apoptosis occurred simultaneously, implying that suppression of growth depended on enhancement of cell 

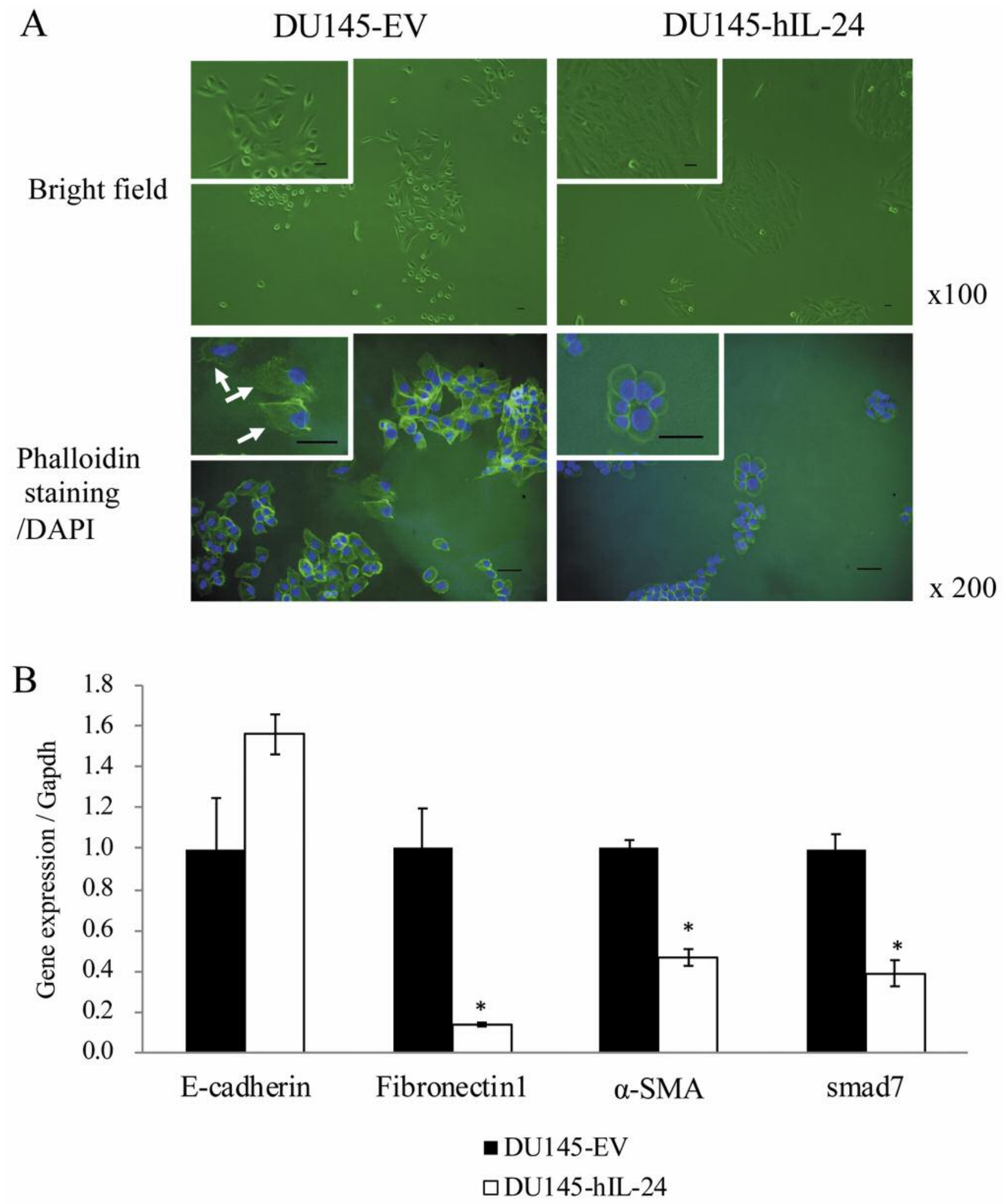

Figure 4. Morphological changes of DU145 cells after transduction of hIL-24. Observation of DU145-hIL-24 and DU145-EV cells in bright field (upper). Actin filament staining by fluorescent phalloidin (green), with counterstaining of cell nucleus by DAPI (blue) (lower) (A). Epithelial marker and mesenchymal marker expression was determined by real-time RT-PCR (B). Scale bars $50 \mu \mathrm{m}$. Arrows show actin filament formation. Data are the mean $\pm S D$ of three experiments. ${ }^{*} p<0.05$ (compared to DU145-EV cells). 
death via apoptosis rather than inhibition of mitosis. It was reported that transduction of IL-24 into human melanoma cells using an adenoviral vector induced growth suppression and apoptosis ranging between -60 and $>80 \%$ versus control cells (17). This report indicates a difference between the antitumor effect of retrovirus vector-mediated and adenovirus vector-mediated transfection of IL-24. Kreis et al. concluded that the antitumor effect of IL-24 is mediated by a specific pathway after transfection with an adenoviral vector, and the same effect cannot be obtained by only transduction of IL-24 DNA (18). Hence, the effect of introducing IL-24 without an adenoviral vector might be limited, suggesting that it would be less efficient to only induce IL-24 DNA or plasmid-mediated gene expression, and that strong induction of apoptosis requires another cooperative factor.

In the present study, we observed a decrease of fibronectin 1 and stress fibers in DU145 cells transfected with IL-24 using a retroviral vector. In addition, actin fiber formation was decreased by introduction of IL-24, indicating that tumor cell motility was probably suppressed. Moreover, mRNA analysis showed mesenchymal marker downregulation combined with epithelial marker up-regulation. Thus, introduction of IL-24 had the effect of suppressing cell motility and altering anchorage dependence. In the process of metastasis, tumor cells acquire the ability to cross the basement membrane and cleave stromal tissue (19), suggesting that regulation of anchorage independence by IL24 could decrease tumor malignancy.

Our data showed that DU145-IL-24 cells secreted IL-24 protein into the culture medium. Since cytokines are generally secreted proteins and act via specific receptors, we examined the effect of adding rhIL-24 to cell cultures. Contrary to our expectation, rhIL-24 did not exert an antitumor effect and DU145 cells did not show strong expression of I1-24 receptors. Accordingly, it seems that IL-24 transduced by our retroviral vector acted via an intracellular pathway, rather than via an extracellular pathway. The primary sequence of human IL-24 differs from homologous cytokines, including IL-10 and the IL19 subfamily, because it has three consensus N-linked glycosylation sites and the potential to form a single disulfide bond (20). It was reported that IL-24 is modified by glycosylation, S-S bridging, and phosphorylation, with glycosylation and S-S bridging being essential for secretion and activation of IL-24 protein (21). Panneerselvam et al. investigated the phosphorylation of IL-24, and reported that phosphorylated IL-24 suppressed the oncogene pAkt and promoted mTOR-mediated induction of apoptosis (22). Also, intracellular IL-24 protein was reported to interact directly with protein kinase RNA-activated, a double-stranded RNA-activated protein kinase (23). However, the mechanisms involved in phosphorylation of IL-24 protein and the subsequent intracellular signaling pathways are largely unknown and further investigation is required.

In conclusion, we showed that retrovirus-mediated constitutive overexpression of IL-24 suppressed prostate cancer cell proliferation and attenuated malignancy via modulation of mesenchymal marker expression and stress fiber formation. It is thought that IL-24 acts on various types of tumor cells, thus our findings that suggest elucidation of IL-24 functions not mediated via its receptors could lead to identification of potential anticancer targets.

\section{Authors' Contributions}

Hidero Kitasato contributed to the conception and design of the study and revised the manuscript. Shotaro Maehana and Yuta Matsumoto performed the experiments. Fumiaki Kojima helped the phalloidin staining and revised the manuscript. All Authors approved the final manuscript.

\section{Acknowledgements}

The Authors would like to thank M. Nakamura (Kitasato University School of Allied Health Science) and T. Matsumoto (Kitasato University School of Medicine) for helpful discussion. This work was supported by JSPS KAKENHI Grant Number JP 26430169.

\section{References}

1 Siegel RL, Miller KD and Jemal A: Cancer statistics, 2017. CA Cancer J Clin 67(1): 7-30, 2017. PMID: 28055103. DOI: $10.3322 /$ caac. 21387

2 Loberg RD, Logothetis CJ, Keller ET and Pienta KJ: Pathogenesis and treatment of prostate cancer bone metastases: Targeting the lethal phenotype. J Clin Oncol 23(32): 8232-8241, 2005. PMID: 16278478. DOI: 10.1200/JCO .2005.03.0841

3 Potosky AL, Miller BA, Albertsen PC and Kramer BS: The role of increasing detection in the rising incidence of prostate cancer. JAMA 273(7): 548-552, 1995. PMID: 7530782.

4 Carlsson S, Assel M, Ulmert D, Gerdtsson A, Hugosson J, Vickers A and Lilja H: Screening for prostate cancer starting at age 50-54 years. A population-based cohort study. Eur Urol 71(1): 46-52, 2017. PMID: 27084245. DOI: 10.1016/j.eururo. 2016.03.026

5 Sweeney CJ, Chen YH, Carducci M, Liu G, Jarrard DF, Eisenberger M, Wong YN, Hahn N, Kohli M, Cooney MM, Dreicer R, Vogelzang NJ, Picus J, Shevrin D, Hussain M, Garcia JA and DiPaola RS: Chemohormonal therapy in metastatic hormone-sensitive prostate cancer. N Engl J Med 373(8): 737746, 2015. PMID: 26244877. DOI: 10.1056/NEJMoa1503747

6 Kasper S and Cookson MS: Mechanisms leading to the development of hormone-resistant prostate cancer. Urol Clin North Am 33(2): 201-210, vii, 2006. PMID: 16631458. DOI: 10.1016/j.ucl.2005.12.010

7 Chen J, Caspi RR and Chong WP: IL-20 receptor cytokines in autoimmune diseases. J Leukoc Biol 104(5): 953-959, 2018. PMID: 30260500. DOI: 10.1002/JLB.MR1117-471R 
8 Wolk K, Kunz S, Asadullah K and Sabat R: Cutting edge: Immune cells as sources and targets of the IL-10 family members? J Immunol 168(11): 5397-5402, 2002. PMID: 12023331.

9 Pestka S, Krause CD, Sarkar D, Walter MR, Shi Y and Fisher PB: Interleukin-10 and related cytokines and receptors. Annu Rev Immunol 22: 929-979, 2004. PMID: 15032600. DOI: 10.1146/annurev.immunol.22.012703.104622

10 Kragstrup TW, Andersen T, Heftdal LD, Hvid M, Gerwien J, Sivakumar P, Taylor PC, Senolt L and Deleuran B: The IL-20 Cytokine family in rheumatoid arthritis and spondyloarthritis. Front Immunol 9: 2226, 2018. PMID: 30319661. DOI:10.3389/ fimmu.2018.02226

11 Dumoutier L, Leemans C, Lejeune D, Kotenko SV and Renauld JC: Cutting edge: Stat activation by IL-19, IL-20 and mda-7 through IL-20 receptor complexes of two types. J Immunol 167(7): 3545-3549, 2001. PMID: 11564763

12 Fisher PB and Grant S: Effects of interferon on differentiation of normal and tumor cells. Pharmacol Ther 27(2): 143-166, 1985. PMID: 2412243.

13 Jiang H, Su ZZ, Lin JJ, Goldstein NI, Young CS and Fisher PB: The melanoma differentiation associated gene mda-7 suppresses cancer cell growth. Proc Natl Acad Sci USA 93(17): 9160-9165, 1996. PMID: 8799171.

14 Ekmekcioglu S, Ellerhorst J, Mhashilkar AM, Sahin AA, Read CM, Prieto VG, Chada S and Grimm EA: Down-regulated melanoma differentiation associated gene (mda-7) expression in human melanomas. Int J Cancer 94(1): 54-59, 2001. PMID: 11668478, DOI: $10.1002 / \mathrm{ijc} .1437$

15 Frewer NC, Ye L, Sun PH, Owen S, Ji K, Frewer KA, Hargest R and Jiang WG: Potential implication of IL-24 in lymphangiogenesis of human breast cancer. Int J Mol Med 31(5): 1097-1104, 2013. PMID: 23546515. DOI: 10.3892/ijmm.2013.1319

16 Bhutia SK, Das SK, Azab B, Menezes ME, Dent P, Wang XY, Sarkar D and Fisher PB: Targeting breast cancer-initiating/stem cells with melanoma differentiation-associated gene-7/interleukin24. Int J Cancer 133(11): 2726-2736, 2013. PMID: 23720015 DOI: $10.1002 / \mathrm{ijc} .28289$

17 Lebedeva IV, Su ZZ, Chang Y, Kitada S, Reed JC and Fisher PB: The cancer growth suppressing gene mda-7 induces apoptosis selectively in human melanoma cells. Oncogene 21(5): 708-718, 2002. PMID: 11850799. DOI: 10.1038/sj.onc.1205116
18 Kreis S, Philippidou D, Margue C and Behrmann I: IL-24: A classic cytokine and/or a potential cure for cancer? J Cell Mol Med 12(6A): 2505-2510, 2008. PMID: 18505472. DOI: 10.1111/ j.1582-4934.2008.00372.x

19 Procacci P, Moscheni C, Sartori P, Sommariva M and Gagliano $\mathrm{N}$ : Tumor stroma cross-talk in human pancreatic ductal adenocarcinoma: A focus on the effect of the extracellular matrix on tumor cell phenotype and invasive potential. Cells 7(10): pii: E158, 2018. PMID: 30301152. DOI: 10.3390/cells7100158

20 Fuson KL, Zheng M, Craxton M, Pataer A, Ramesh R, Chada S and Sutton RB: Structural mapping of post-translational modifications in human interleukin-24: Role of N-linked glycosylation and disulfide bonds in secretion and activity. J Biol Chem 284(44): 30526-30533, 2009. PMID: 19734147. DOI: 10.1074/jbc.M109.036061

21 Sauane M, Gopalkrishnan RV, Sarkar D, Su ZZ, Lebedeva IV, Dent P, Pestka S and Fisher PB: Mda-7/IL-24: Novel cancer growth suppressing and apoptosis inducing cytokine. Cytokine Growth Factor Rev 14(1): 35-51, 2003. PMID: 12485618.

22 Panneerselvam J, Shanker M, Jin J, Branch CD, Muralidharan R, Zhao YD, Chada S, Munshi A and Ramesh R: Phosphorylation of interleukin (IL)-24 is required for mediating its anti-cancer activity. Oncotarget 6(18): 16271-16286, 2015. PMID: 26009991. DOI: 10.18632/oncotarget.3977

23 Pataer A, Vorburger SA, Chada S, Balachandran S, Barber GN, Roth JA, Hunt KK and Swisher SG: Melanoma differentiationassociated gene-7 protein physically associates with the doublestranded RNA-activated protein kinase PKR. Mol Ther 11(5): 717723, 2005. PMID: 15851010. DOI: 10.1016/j.ymthe.2005.01.018

Received February 26, 2019

Revised April 29, 2019

Accepted May 2, 2019 